\title{
Proteína e energia na alimentação de pacus criados em tanques-rede ${ }^{1}$
}

\section{Arcangelo Augusto Signor ${ }^{2}$, Wilson Rogério Boscolo ${ }^{3}$, Aldi Feiden ${ }^{3}$, Fábio Bittencourt ${ }^{4}$, Anderson Coldebella ${ }^{5}$, Adilson Reidel ${ }^{5}$}

\author{
${ }^{1}$ Itaipu Binacional e Fundação Universitária de Toledo. \\ 2 Doutorando em Zootecnia, UEM. Rua da Faculdade, 645, CEP: 85900-000, Toledo, Paraná. \\ 3 Programa de Pós-Graduação em Zootecnia e em Recursos Pesqueiros e Engenharia de Pesca - Universidade Estadual do Oeste do Paraná. \\ ${ }^{4}$ Doutorando em Aquicultura, CAUNESP/UNESP. \\ ${ }^{5}$ Instituto Federal do Paraná, Foz do Iguaçu, Paraná.
}

RESUMO - O objetivo neste trabalho foi avaliar o desempenho de pacus (Piaractus mesopotamicus) criados em tanquesrede e alimentados com dietas contendo níveis de proteína bruta (PB) e energia digestível (ED). Foram utilizados 3.960 peixes com 293,38 $\pm 5,67 \mathrm{~g}$ de peso inicial, distribuídos em 18 tanques-rede de $5 \mathrm{~m}^{3}$, com 220 peixes por unidade experimental (44 peixes $/ \mathrm{m}^{3}$ ), em esquema fatorial $3 \times 2$, composto de três níveis de proteína bruta $(25,30$ e $35 \%$ ) e dois de energia digestível $(3.250$ e $3.500 \mathrm{kcal} / \mathrm{kg}$ ). O arraçoamento foi realizado quatro vezes ao dia (às $9 \mathrm{~h}, 11 \mathrm{~h} 30 \mathrm{~min}, 14 \mathrm{~h}$ e $17 \mathrm{~h}$ ) até a saciedade aparente dos animais. Não foram observadas diferenças no ganho de peso, na taxa de sobrevivência, na conversão alimentar aparente nem na taxa de crescimento específico. No entanto, houve diferença na deposição de gordura visceral, que fo maior nos animais alimentados com as rações de maior nível energético. Também não foi observada influência dos níveis de proteína e energia da dieta nos teores de umidade, proteína bruta, matéria mineral e lipídio dos filés. Rações contendo $25 \%$ de proteína bruta e $3.250 \mathrm{kcal} / \mathrm{kg}$ de energia digestível promovem melhores resultados de desempenho.

Palavras-chave: espécies nativas, exigência nutricional, juvenis, nutrição, Piaractus mesopotamicus, tanques-rede

\section{Protein and energy on food of pacu fish raised in cages}

\begin{abstract}
The aim of this study was to evaluate the performance of pacu (Piaractus mesopotamicus) raised in cages and fed diets containing levels of crude protein (CP) and digestible energy (DE). It was used 3.960 fish with an average initial weight of $293.38 \pm 5.67 \mathrm{~g}$, distributed in 18 net-ponds with $5 \mathrm{~m}^{3}$, with 220 fish per experimental unit $\left(44 \mathrm{fish} / \mathrm{m}^{3}\right)$ in a $3 \times 2$ factorial scheme composed of three levels of crude protein $(25,30$ and $35 \%)$ and two levels of digestible energy $(3,250$ and 3,500 kcal/kg). Feeding was performed four times a day (9:00 a.m., 11:30 a.m., 2:00 p.m. and 5:00 p.m.) until apparent satiety of the animals. No differences were observed for weight gain, survival rate, apparent feed conversion and specific growing rate. Nevertheless, there was a difference on visceral fat deposition which was higher for animals fed ration with higher energy level. It was not observed influence of levels of protein and energy of the diet in contents of moisture, crude protein, mineral matter and lipids in the fish fillets, either. Rations containing $25 \%$ of crude protein and $3,250 \mathrm{kcal} / \mathrm{kg}$ of digestible energy promote better performance results.
\end{abstract}

Key Words: cages, juveniles, native species, nutrition, nutritional requirement, Piaractus mesopotamicus

\section{Introdução}

O pacu (Piaractus mesopotamicus) pertence à ordem Characiformes, que inclui os peixes de maior valor comercial na pesca e na piscicultura brasileira (Urbinati \& Gonçalves, 2005). A subfamília Myleinae, que inclui o pacu, é representada por peixes herbívoros e alimenta-se no meio natural de frutos e sementes, entre outros (Nakatani et al., 2001).

O cultivo de peixes em tanque-rede tem se destacado na aquicultura nacional por ser um sistema de produção que proporciona altos índices de biomassa, otimizando a unidade produtora em pouco espaço físico. Além disso, possibilita o uso de águas de reservatórios de hidrelétricas para aquicultura conforme previsto no Decreto $\mathrm{N}^{\circ} 4.895$, de 25 novembro de 2003, que autoriza o uso dos corpos-d'água da União para prática da aquicultura.

Determinar um único valor de proteína dietética para todas as fases de vida do animal é impraticável (Brown \& Robinson, 1989), pois a temperatura da água, o tamanho do peixe, o arraçoamento, a qualidade da proteína utilizada e a participação de fontes energéticas não-proteicas 
(Robinson \& Wilson, 1985) influenciam as exigências nutricionais dos peixes. As fontes energéticas não-proteicas têm grande importância, pois as concentrações de proteína e energia para peixes devem estar balanceadas para proporcionar bons índices de conversão alimentar e retenção de proteína na carcaça (Ellis \& Reigh, 1991). Gonçalves et al. (2009) relataram que o nível de energia não alterou o desempenho de tilápias, porém houve redução no consumo de alimento e na taxa de eficiência proteica, além de aumento no consumo de proteína, quando se elevaram os níveis de proteína digestível da na dieta.

A relação energia/proteína e a disponibilidade de nutrientes devem ser adequadas às exigências da espécie para que apresentem boas taxas de crescimento (Hayashi et al., 2002). A elevada disponibilidade de energia nas rações e elevada relação energia/proteína resultam na baixa ingestão de proteína e dos nutrientes essenciais da dieta (Chou \& Shiau, 1996), ocasionando deposição de gordura visceral e/ ou corporal em várias espécies (Macgoogan \& Reigh, 1996; Mukhopadhyay \& Ray, 1997) e possível perda de qualidade da carne devido à elevada oxidação de ácidos graxos durante o armazenamento. Por outro lado, dietas com deficiência energética favorecem a síntese de energia a partir das proteínas, elevando os índices de conversão alimentar e o custo de produção (Lowell, 1989), além de aumentar a excreção de compostos nitrogenados (Pezzato et al., 2002; Boscolo et al., 2005).

Este trabalho foi realizado com o objetivo de avaliar o desempenho de pacus (P. mesopotamicus) criados em tanques-rede e alimentados com dietas contendo diferentes níveis de proteína e energia.

\section{Material e Métodos}

O experimento foi realizado em tanques-rede no Centro de Desenvolvimento de Tecnologia para Piscicultura, localizado no Refúgio Biológico do município de Santa Helena, Paraná, entre as coordenadas geográficas W 54 21' 196,

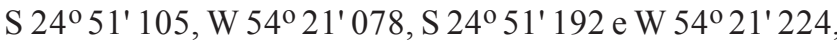
$\mathrm{S} 24^{\circ} 51^{\prime} 143$, por um período de 154 dias.

Foram utilizados 3.960 peixes com peso inicial de $293,38 \pm 5,67 \mathrm{~g}$, distribuídos em 18 tanques-rede de $5 \mathrm{~m}^{3}$, em delineamento inteiramente casualizado, em esquema fatorial $3 \times 2$, com três níveis de proteína bruta $(25,30$ e $35 \%$ ) e dois de energia digestível (3.250 e $3.500 \mathrm{kcal} / \mathrm{kg}$ ), totalizando seis dietas, cada uma avaliada com três repetições, considerando unidade experimental um tanque contendo 220 peixes, resultando em 44 peixes $/ \mathrm{m}^{3}$.

Para fabricação das rações, os alimentos foram pesados e processados em moinho do tipo martelo com peneira de

Tabela 1 - Composição percentual das rações experimentais com diferentes níveis de proteína e energia (\%MN)

\begin{tabular}{|c|c|c|c|c|c|c|}
\hline \multirow[t]{4}{*}{ Ingrediente $(\%)$} & \multicolumn{6}{|c|}{ Nível de energia da dieta } \\
\hline & \multicolumn{3}{|c|}{$3.250 \mathrm{kcal} / \mathrm{kg}$} & \multicolumn{3}{|c|}{$3.500 \mathrm{kcal} / \mathrm{kg}$} \\
\hline & \multicolumn{6}{|c|}{ Nível de proteína (\%) } \\
\hline & 25 & 30 & 35 & 25 & 30 & 35 \\
\hline Antioxidante (BHT) & 0,030 & 0,030 & 0,030 & 0,030 & 0,030 & 0,030 \\
\hline Calcário calcítico & 0,027 & 0,107 & 0,188 & 0,000 & 0,081 & 0,161 \\
\hline Fosfato bicálcico & 0,496 & 0,249 & 0,002 & 0,536 & 0,290 & 0,043 \\
\hline Arroz quirera & 30,000 & 30,000 & 30,000 & 30,000 & 30,000 & 30,000 \\
\hline Farinha de carne e ossos & 4,787 & 4,787 & 4,787 & 4,787 & 4,787 & 4,787 \\
\hline Farinha de peixe & 3,334 & 3,334 & 3,334 & 3,334 & 3,334 & 3,334 \\
\hline Farinha de vísceras de aves & 15,000 & 15,000 & 15,000 & 15,000 & 15,000 & 15,000 \\
\hline Farelo de soja & 14,379 & 27,215 & 40,051 & 15,390 & 28,225 & 41,061 \\
\hline Milho & 30,673 & 18,146 & 5,618 & 25,057 & 12,528 & 0,001 \\
\hline Óleo de soja & 0,323 & 0,182 & 0,041 & 4,916 & 4,775 & 4,633 \\
\hline Suplemento mineral vitamínico ${ }^{1}$ & 0,400 & 0,400 & 0,400 & 0,400 & 0,400 & 0,400 \\
\hline Antifúngico (propionato de cálcio) & 0,050 & 0,050 & 0,050 & 0,050 & 0,050 & 0,050 \\
\hline Sal comum & 0,500 & 0,500 & 0,500 & 0,500 & 0,500 & 0,500 \\
\hline \multicolumn{7}{|l|}{ Nutriente } \\
\hline Amido (\%) & 41,010 & 33,205 & 25,400 & 37,511 & 29,705 & 21,901 \\
\hline Cálcio $(\%)$ & 1,450 & 1,450 & 1,450 & 1,450 & 1,450 & 1,450 \\
\hline Energia digestível $(\mathrm{kcal} / \mathrm{kg})^{2}$ & 3250 & 3250 & 3250 & 3500 & 3500 & 3500 \\
\hline Proteína bruta $(\%)$ & 25,000 & 30,000 & 35,000 & 25,000 & 30,000 & 35,000 \\
\hline Fibra bruta $(\%)$ & 1,923 & 2,442 & 2,961 & 1,875 & 2,394 & 2,913 \\
\hline Fósforo disponível (\%) & 0,800 & 0,800 & 0,800 & 0,800 & 0,800 & 0,800 \\
\hline Gordura $(\%)$ & 4,279 & 3,879 & 3,479 & 8,645 & 8,245 & 7,845 \\
\hline Ácido linoleico (\%) & 1,242 & 1,019 & 0,796 & 3,623 & 3,399 & 3,176 \\
\hline Lisina $(\%)$ & 1,281 & 1,606 & 1,932 & 1,295 & 1,620 & 1,946 \\
\hline Metionina + cistina $(\%)$ & 0,905 & 1,021 & 1,138 & 0,897 & 1,013 & 1,130 \\
\hline Metionina $(\%)$ & 0,455 & 0,517 & 0,579 & 0,452 & 0,514 & 0,576 \\
\hline
\end{tabular}


malha de $0,8 \mathrm{~mm}$ e posteriormente misturados adicionando os micronutrientes, o antifúngico e, por último, o óleo. As rações foram formuladas para ser isocálcicas e isofosfóricas (Tabela 1) e submetidas ao processo de extrusão com péletes de $4 \mathrm{~mm}$; depois, foram secas, embaladas e identificadas.

$\mathrm{O}$ arraçoamento foi realizado quatro vezes ao dia, às 9 h, 1 h30min, 14 h e $17 \mathrm{~h}$, até a saciedade aparente dos animais. Foram realizadas biometrias a cada 28 dias, para acompanhamento do crescimento dos peixes, com captura mínima de $10 \%$ dos animais, de forma aleatória.

$\mathrm{O} \mathrm{pH}$, a condutividade elétrica $(\mu \mathrm{S} / \mathrm{cm})$ e o oxigênio dissolvido $(\mathrm{mg} / \mathrm{L})$ da água foram medidos quinzenalmente, enquanto a temperatura $\left({ }^{\circ} \mathrm{C}\right)$ e a transparência da água $(\mathrm{m})$ foram monitoradas diariamente pela manhã $(9 \mathrm{~h})$ eà tarde $(17 \mathrm{~h})$.

Ao final do período experimental, os peixes foram mantidos em jejum por 24 horas e posteriormente foram contados e pesados. Foram coletados dez animais de cada tanque, acondicionados em gelo e transportados ao Laboratório de Tecnologia do Pescado da Unioeste, para avaliação do rendimento e análises da composição química dos filés dos pacus.

Foram avaliados os índices zootécnicos de ganho de peso, conversão alimentar aparente, taxas de sobrevivência e de crescimento específico e os rendimentos de carcaça, tronco limpo e filé, além das porcentagens de cabeça, gordura visceral e índice hepatossomático. Posteriormente, foram realizadas análises bromatológicas dos teores de umidade, proteína bruta, lipídios e matéria mineral dos filés dos peixes, segundo metodologia proposta pela AOAC (2000).

Ao final do período experimental, os dados obtidos foram submetidos à análise de variância a $5 \%$ de probabilidade, em distribuição fatorial e, em caso de diferenças, foi aplicado o teste Tukey, pelo programa estatístico SISVAR.

\section{Resultados e Discussão}

Os valores médios de temperatura, $\mathrm{pH}$, condutividade elétrica, oxigênio dissolvido e transparência da água durante o experimento foram de $24,21 \pm 3,50^{\circ} \mathrm{C} ; 7,42 \pm 0,22$; $55,51 \pm 6,08 \mathrm{mS} / \mathrm{cm} ; 7,27 \pm 1,04 \mathrm{mg} / \mathrm{L}$; e $2,22 \pm 0,42 \mathrm{~m}$, respectivamente. Esses valores encontram-se na faixa recomendada para o cultivo de peixes em clima tropical (Boyd, 1990; Sipaúba-Tavares, 1995), no entanto, houve grande variação da temperatura durante o experimento, com diminuição linear conforme se passaram os dias de cultivo (Figura 1), visto que o experimento foi iniciado em janeiro e encerrado em julho.

Os resultados de ganho de peso (Tabela 2) observados neste experimento são semelhantes aos encontrados por Fernandes et al. (2001), que, em experimento com juvenis de pacu, avaliaram três níveis de PB $(18,22$ e $26 \%$ de PB) em dietas isoenergéticas com $4.200 \mathrm{kcal} / \mathrm{kg}$ de $\mathrm{EB}$ e não observaram diferença no ganho de peso dos animais. Por outro lado, Fernandes et al. (2000) avaliaram os níveis de 22, 26 e $30 \%$ de PB em rações isoenergéticas com $4.200 \mathrm{kcal} / \mathrm{kg}$ de energia bruta para alevinos de pacu e observaram melhores resultados de ganho de peso nos animais alimentados com 26 e $30 \%$ de $P B$, diferindo $(P<0,05)$ daqueles que receberam rações com $22 \%$ de $\mathrm{PB}$.

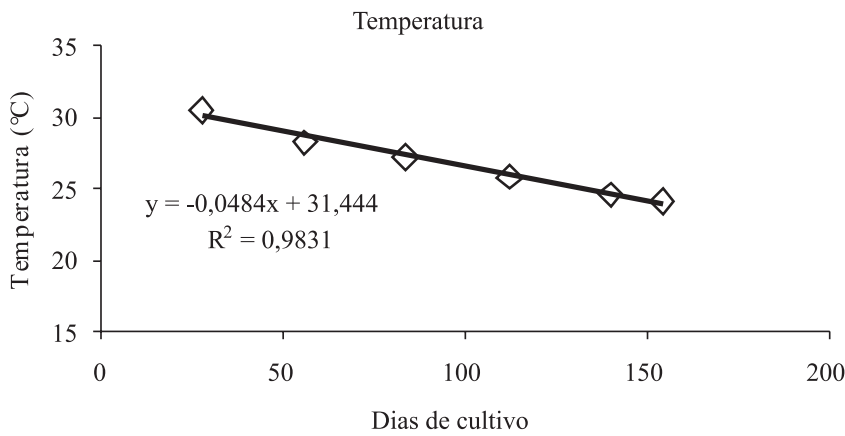

Figura 1 - Valores médios de temperatura durante o cultivo.

Tabela 2 - Desempenho produtivo de pacus cultivados em tanques-rede com diferentes níveis de proteína e energia na dieta

\begin{tabular}{lcccc}
\hline Item & \multicolumn{3}{c}{ Parâmetro } \\
\cline { 2 - 5 } & Ganho de peso & Conversão alimentar & Sobrevivência & Taxa de crescimento específico \\
\hline Proteína bruta & $0,2680 \mathrm{~ns}$ & $0,3137 \mathrm{~ns}$ & $0,6610 \mathrm{~ns}$ & $0,2209 \mathrm{~ns}$ \\
Energia digestível & $0,7829 \mathrm{~ns}$ & $0,4232 \mathrm{~ns}$ & $0,1358 \mathrm{~ns}$ & $0,5638 \mathrm{~ns}$ \\
PB*ED & $0,9862 \mathrm{~ns}$ & $0,9946 \mathrm{~ns}$ & $0,8806 \mathrm{~ns}$ & 5,85 \\
CV & 8,31 & 10,03 & 1,08 & 0,67 \\
Proteína bruta $(\%)$ & 528,84 & 3,16 & 99,32 & 0,67 \\
25 & 528,07 & 3,05 & 99,40 & 0,70 \\
30 & 567,06 & 2,88 & 98,87 & 0,67 \\
35 & & & & 0,68 \\
Energia digestível $(\mathrm{kcal} / \mathrm{kg})$ & 538,34 & 3,09 & 98,79 & 99,60 \\
3.250 & 544,31 & 2,97 & & \\
3.500 & & &
\end{tabular}


Vidal Jr. et al. (1998) avaliaram os níveis de 18, 21, 24, 27 e $30 \%$ de PB em rações com $3.100 \mathrm{kcal} / \mathrm{kg}$ de EM para juvenis de tambaqui e observaram efeito quadrático no ganho de peso dos animais, com maior valor no nível estimado de $25,01 \%$ de PB. Resultados experimentais com efeitos quadráticos comprovam que, a partir de determinado nível de nutrientes, a dieta passa a ser prejudicial ao crescimento, pois os animais demandam energia para metabolizar e excretar o excesso de nutrientes da dieta, fato não observado neste trabalho.

Camargo et al. (1998) avaliaram rações isoproteicas, com 2,850,3.000, 3.150 e $3.300 \mathrm{kcal} / \mathrm{kg}$ de EM, para juvenis de tambaqui e observaram que a dieta com $3.300 \mathrm{kcal} / \mathrm{kg}$ de EM promoveram melhor ganho de peso.

A taxa de sobrevivência não diferiu $(\mathrm{P}>0,05)$ entre os níveis proteicos e energéticos estudados, resultados que se assemelham aos observados por Gomes et al. (2004), Brandão et al. (2004) e Chagas et al. (2005), que avaliaram o desempenho de tambaqui em tanques-rede e não observaram diferença na taxa de sobrevivência.

Os índices de conversão alimentar foram semelhantes aos relatados por Fernandes et al. (2001), que avaliaram 18, 22 e $26 \%$ de PB na dieta e obtiveram índices de 4,14,3,51 e 3,34 para a conversão alimentar, que não diferiu $(\mathrm{P}>0,05)$ entre os níveis estudados. Resultados semelhantes, em que o nível de proteína bruta não influenciou a conversão alimentar em outras espécies foram obtidos por Vidal Jr. et al. (1998) para o tambaqui, Teixeira et al. (2010) e Signor et al. (2004) para o jundiá e Furuya et al. (2000) para a tilápias-do-nilo, porém, os valores de conversão alimentar observados neste trabalho e aqueles relatados por Fernandes et al. (2001) são superiores aos obtidos em outras espécies, provavelmente em virtude do manejo alimentar utilizado, tendo em vista a ocorrência de sobras de ração durante os arraçoamentos.

Por outro lado, Fernandes et al. (2000) avaliaram níveis de 22,26 e $30 \%$ de PB em rações para pacus e observaram valores de 1,$44 ; 1,27 ; \mathrm{e} 1,19$, com os melhores resultados nos níveis de 26 e $30 \%$ de $\mathrm{PB}$, diferindo $(\mathrm{P}<0,05)$ dos peixes alimentados com rações contendo $22 \%$ de PB. Bomfim et al. (2005) avaliaram os níveis de 18, 22, 26 e 30\% de PB e 2.700 e $3.000 \mathrm{kcal} / \mathrm{kg}$ de ED para alevinos de curimbatá e observaram efeito quadrático, com os melhores níveis de PB e ED de $26,05 \%$ e $2.700 \mathrm{kcal} / \mathrm{kg}$, respectivamente. Sá \& Fracalossi (2002) relataram que o nível de $26 \%$ de $\mathrm{PB}$ em rações com $3.000 \mathrm{kcal} / \mathrm{kg}$ de EMé suficiente para atender às exigências de alevinos de piracanjuba e resulta em melhor conversão alimentar.

A taxa de crescimento específico encontrada neste experimento é semelhante à observada por Fernandes et al. (2001), que relatam não ter observado diferença $(P>0,05) \mathrm{em}$ estudo no qual avaliaram níveis de proteína na dieta. Por outro lado, são contrários aos observados por Fernandes et al. (2000), que observaram melhores resultados no nível de $30 \%$ de $\mathrm{PB}$, que não diferiu $(\mathrm{P}<0,05)$ do nível de $26 \%$ de $\mathrm{PB}$.

Quando a relação energia:proteína da dieta é elevada, as exigências proteicas dos animais podem não ser satisfeitas (Pezzato et al., 2001), o que prejudica seu desempenho. A relação energia:proteína variou de 9,3 a $14 \mathrm{kcal} \mathrm{de} \mathrm{ED/g} \mathrm{de} \mathrm{PB}$ para as rações utilizadas neste experimento e está de acordo com relatos de Cho \& Kaushik (1990) de que a relação energia:proteína para peixes tem sido determinada entre 6,90 e 14,25 kcal ED/g PB ou PD e que esta variação pode estar relacionada ao hábito alimentar dos peixes, uma vez que os carnívoros apresentam menor relação, pois aproveitam mais eficientemente a energia proveniente de gorduras, em comparação aos peixes herbívoros que aproveitam com maior eficiência os carboidratos como fonte energética.

Os valores médios de gordura visceral (Tabela 3 ) não diferiram $(\mathrm{P}>0,05)$ entre os níveis proteicos, ao contrário do nível energético, uma vez que os maiores valores foram observados nos peixes alimentados com dietas contendo $3.500 \mathrm{kcal} / \mathrm{kg}$ de energia digestível.

O rendimento médio de carcaça foi semelhante ao reportado por Bombardelli et al. (2007), de $84,40 \%$ em pacus, porém são inferiores aos relatados por Faria et al. (2003), de $88,89 \%$.

Os resultados de tronco limpo são de grande valia para a indústria de pescados, pois representam a parte útil do pescado utilizado para consumo humano. Neste trabalho, os valores obtidos para tronco limpo foram semelhantes aos descritos por Bombardelli et al. (2007) para a espécie. Segundo Contreras-Guzmán (1994), o maior rendimento do pescado em pacus, piavuçus, curimbatás e outros pode ser explicado pela baixa porcentagem de cabeça, que é de aproximadamente $15 \%$. Essa hipótese foi verificada em pacus e tilápias por Faria et al. (2003), que relataram que o maior rendimento de tronco limpo do pacu é ocasionado pela baixa porcentagem de cabeça dessa espécie.

O rendimento de filé assemelha-se ao de 46 a 51\%, verificado por Faria et al. (2003) para pacus e provavelmente está relacionado ao método de filetagem. São superiores, no entanto, aos observados por Bombardelli et al. (2007), de 22,41 e $24,09 \%$, embora esses autores tenham avaliado os filés sem espinhas, pois foram retirados somente sobre as costelas, diferente da metodologia utilizada neste trabalho.

As diferenças $(\mathrm{P}<0,05)$ na porcentagem de gordura visceral entre os níveis energéticos avaliados pode ser explicada pelo fato de os peixes utilizarem essa energia para manutenção e deposição proteica, assim, o excesso é armazenado na forma de gordura, visceral e/ou intramuscular ou ainda subcutânea. 
Não foram observadas diferenças $(\mathrm{P}>0,05)$ para a umidade nem para os teores de proteína bruta, matéria mineral e lipídios do filé entre os níveis de proteína bruta e energia digestível avaliados (Tabela 4). Esses resultados divergem dos relatos de Fernandes et al. (2001) de que os maiores teores de PB na carcaça são obtidos quando os peixes são alimentados com dietas com $26 \%$ de $\mathrm{PB}$, diferindo $(\mathrm{P}<0,05)$ da proteína corporal daqueles alimentados com $18 \%$ de PB nas rações.

$\mathrm{O}$ aumento nos níveis de $\mathrm{PB}$ nas dietas não promoveu diferença $(\mathrm{P}<0,05)$ na concentração de lipídios dos filés dos pacus, resultados semelhantes aos observados por Fernandes et al. $(2000 ; 2001)$ para alevinos e juvenis de pacu, respectiva- mente. Também Sá \& Fracalossi (2002), em alevinos de piracanjuba, e Botaro et al. (2007), em juvenis de tilápia-donilo, relataram que o aumento nos níveis de $\mathrm{PB}$ nas rações não influenciou na deposição de lipídios na carcaça dos animais.

Os resultados obtidos neste trabalho indicam que os níveis proteicos e energéticos não influenciam no desempenho zootécnico, no rendimento de carcaça nem na composição do filé. Contudo, a utilização de rações com maior nível energético resulta em maior porcentagem de gordura visceral em pacus cultivados em tanques-rede, por isso, são ainda necessário estudos para avaliar os níveis proteicos e energéticos nas formulações de rações visando melhor desempenho dos peixes.

Tabela 3 - Rendimento corporal de pacus cultivados em tanques-rede com diferentes níveis de proteína e energia na dieta

\begin{tabular}{|c|c|c|c|c|c|c|}
\hline \multirow[t]{2}{*}{ Item } & \multicolumn{6}{|c|}{ Parâmetro (\%) } \\
\hline & $\begin{array}{l}\text { Rendimento } \\
\text { de carcaça }\end{array}$ & $\begin{array}{l}\text { Tronco } \\
\text { limpo }\end{array}$ & $\begin{array}{l}\text { Rendimenento } \\
\text { de filé }\end{array}$ & $\begin{array}{l}\text { Porcentagem } \\
\text { de cabeça }\end{array}$ & $\begin{array}{l}\text { Porcentagem de } \\
\text { gordura visceral }\end{array}$ & $\begin{array}{c}\text { Índice } \\
\text { hepatossomático }\end{array}$ \\
\hline Energia digestível & $0,081 \mathrm{~ns}$ & $1,452 \mathrm{~ns}$ & $0,040 \mathrm{~ns}$ & $2,225 \mathrm{~ns}$ & $3,977 *$ & $1,245 \mathrm{~ns}$ \\
\hline$P B * E D$ & $0,218 \mathrm{~ns}$ & $0,084 \mathrm{~ns}$ & $1,557 \mathrm{~ns}$ & $1,690 \mathrm{~ns}$ & $1,038 \mathrm{~ns}$ & $1,495 \mathrm{~ns}$ \\
\hline Coeficiente de variação & 4,780 & 5,370 & 4,280 & 12,340 & 24,070 & 22,140 \\
\hline \multicolumn{7}{|l|}{ Proteína bruta $(\%)$} \\
\hline 30 & 84,94 & 60,71 & 45,86 & 15,04 & 6,17 & 1,70 \\
\hline 35 & 84,73 & 60,37 & 46,15 & 15,28 & 6,66 & 1,74 \\
\hline \multicolumn{7}{|c|}{ Energia digestível (kcal/kg) } \\
\hline 3.250 & 85,01 & 60,28 & 45,91 & 14,99 & $6,22 \mathrm{a}$ & 1,78 \\
\hline 3.500 & 84,69 & 59,23 & 45,80 & 14,89 & $7,97 \mathrm{~b}$ & 1,66 \\
\hline
\end{tabular}

$*(\mathrm{P}<0,05)$.

Tabela 4 - Composição química dos filés de pacus cultivados em tanques-rede com diferentes níveis de proteína e energia na dieta (\%MN)

\begin{tabular}{|c|c|c|c|c|}
\hline \multirow[t]{2}{*}{ Item } & \multicolumn{4}{|c|}{ Parâmetro (\%) } \\
\hline & Umidade & Proteína bruta & Matéria mineral & Lipídios \\
\hline Proteína bruta & $1,596 \mathrm{~ns}$ & $0,138 \mathrm{~ns}$ & $1,250 \mathrm{~ns}$ & $1,897 \mathrm{~ns}$ \\
\hline Energia digestível & $7,136 \mathrm{~ns}$ & $7,838 \mathrm{~ns}$ & $0,975 \mathrm{~ns}$ & $3,419 \mathrm{~ns}$ \\
\hline $\mathrm{PB} * \mathrm{ED}$ & $1,182 \mathrm{~ns}$ & $1,603 \mathrm{~ns}$ & $1,066 \mathrm{~ns}$ & $1,085 \mathrm{~ns}$ \\
\hline Coeficiente de variação & 5,41 & 9,73 & 41,58 & 63,72 \\
\hline \multicolumn{5}{|l|}{ Proteína bruta $(\%)$} \\
\hline 25 & 66,96 & 17,23 & 2,92 & 2,81 \\
\hline 30 & 65,78 & 17,31 & 3,05 & 2,91 \\
\hline 35 & 66,36 & 17,14 & 3,30 & 3,48 \\
\hline \multicolumn{5}{|c|}{ Energia digestível (kcal/kg) } \\
\hline 3250 & 67,13 & 17,60 & 3,19 & 2,76 \\
\hline 3500 & 65,67 & 16,89 & 2,99 & 3,31 \\
\hline
\end{tabular}

\section{Conclusões}

A utilização de $25 \%$ de proteína bruta e $3.250 \mathrm{kcal} / \mathrm{kg}$ de energia digestível atende às exigências nutricionais de pacus tanques-rede.

\section{Agradecimentos}

Ao convênio AS/CT/0100/05, firmado entre a Secretaria Especial de Aquicultura e Pesca da Presidência da República/ Itaipu Binacional/Fundação Universitária de Toledo, e à 
Universidade Estadual do Oeste do Paraná, pela estrutura e pelos insumos fornecidos para realização do experimento.

\section{Referências}

ASSOCIATION OF OFFICIAL ANALYTICAL CHEMISTS - AOAC. Oficial methods of Analysis of Association of Official Analytical Chemists. 17.ed. Arlington: AOAC, 2000. v.1-2. 1115p. BOMBARDELLI, R.A.; BENCKE, B.; SANCHES, E.A. Processamento da carne do pacu (Piaractus mesopotamicus) cultivado em tanques-rede no reservatório de Itaipu. Acta Scientiarum.Animal Sciences, v.29, n.4, p.457-463, 2007.

BOMFIM, M.A.D.; LANNA, E.A.T.; SERAFINI, M.A. et al. Proteína bruta e energia digestível em dietas para alevinos de curimbatá (Prochilodus affins). Revista Brasileira de Zootecnia, v.34, n.6, p.1795-1806, 2005.

BOSCOLO, W.R.; HAYASHI, C.; MEURER, F. Digestibilidade Aparente da energia e nutrientes de alimentos convencionais e alternativos para a tilápia do Nilo (Oreochromis niloticus, L.). Revista Brasileira de Zootecnia, v.13, n.2, p.539-545, 2002.

BOSCOLO,W.R.; HAYASHI, C.; MEURER, F. et al. Farinha de resíduos da indústria de filetagem de tilápias na alimentação de tilápias do Nilo (Oreochromis niloticus), na fase de reversão sexual. Revista Brasileira de Zootecnia, v.34, n.6, p.1807-1812, 2005.

BOTARO, D.; FURUYA, W.M.; SILVA, L.C.R. et al. Redução da proteína da dieta com base no conceito de proteína ideal para tilápias-do-nilo (Oreochromis niloticus) criadas em tanques-rede. Revista Brasileira de Zootecnia, v.36, n.3, p.517-525, 2007.

BOYD, C. Water quality in ponds for aquaculture. Alabama: Birmingham Publiscing, 1990. 482p.

BRANDÃO, F.R.; GOMES, L.C.; CHAGAS, E.C. et al. Densidade de estocagem do tambaqui durante a recria em tanques-rede. Pesquisa Agropecuária Brasileira, v.36, n.4, p.357-362, 2004.

BROWN, P.B.; ROBINSON, E.H. Comparison of practical catfish feeds containin 26 or $30 \%$ protein. Progressive FishCulturist, v.51, p.149-151, 1989.

CAMARGO, A.C.S.; VIDAL JR., M.V.; DONZELE, J.L. et al. Níveis de energia metabolizável para tambaqui (Colossoma macropomum) 180 gramas de peso vivo. 1. Composição das carcaças. Revista Brasileira de Zootecnia, v.27, n.3, p.409-415, 1998.

CHAGAS, E.C.; GOMES, L.C.; JUNIOR, H.M. et al. Desempenho de tambaqui cultivado em tanques-rede em lago de várzea, sob diferentes taxas de alimentação. Pesquisa Agropecuária Brasileira, v.40, n.8, p.833-835, 2005

CHO, C.Y.; KAUSHIK, S.J. Nutritional energetic in fish. Energy and protein utilization in rainbow trout (Salmo gairdneri). World Review Nutrition Diet, n.61, p.132-172, 1990.

CHOU, B.S.; SHIAU, S.Y. Optimal dietary lipid level for growth of juvenile hybrid tilapia, Oreochromis niloticus x Oreochromis aureus. Aquaculture, v.143, n.2, p.185-195, 1996.

CONTRERAS-GUZMÁN, E. Bioquímicos de pescados e derivados. Jaboticabal, FUNEP, 1994. 409p.

ELLIS, S.C.; REIGH, R.C. Effects of dietary lipid and carbohydrate levels on growth and body composition of juvenile red drum (Sciaenops ocellatus). Aquaculture, v.97, p.383-394, 1991.

FARIA, R.H.S.; SOUZA, M.L.R.; WAGNER, P.M. et al. Rendimento do processamento da tilápia do Nilo (Oreochromis niloticus Linnaeus, 1757) e do pacu (Piaractus mesopotamicus Holmberg, 1887). Acta Scientiarum. Animal Science, v.25, n.1, p.21-24, 2003 .

FERNANDES, J.B.K.; CARNEIRO, D.J.; SAKOMURA, N.K. Fontes e níveis de proteína bruta em dietas para alevinos de pacu (Piaractus mesopotamicus), Revista Brasileira de Zootecnia, v.29, n.3, p.646-653, 2000.

FERNANDES, J.B.K.; CARNEIRO, D.J.; SAKOMURA, N.K. Fontes e níveis de proteína bruta em dietas para juvenis de pacu (Piaractus mesopotamicus), Revista Brasileira de Zootecnia, v.30, n.3, p.617-626, 2001.

FURUYA, W.M.; HAYASHI, C.; FURUYA, V.R.B. et al. Exigência de proteína para alevino revertido de tilápia do Nilo (Oreochromis niloticus), Revista Brasileira de Zootecnia, v.29, n.6, p.1912-1917, 2000.

GOMES, L.C.; BRANDÃO, F.R.; CHAGAS, E.C. et al. Efeito do volume do tanque-rede na produtividade de tambaqui (Colossoma macropomum) durante a recria. Acta Amazônica, v.34, n.1, p.11-113, 2004.

GONÇALVES, G.S.; PEZZATO, L.P.; BARROS, M.M. et al. Níveis de proteína digestível e energia digestível em dietas para tilápiasdo-nilo formuladas com base no conceito de proteína ideal. Revista Brasileira de Zootecnia, v.38, n.12, p.2289-2298, 2009.

HAYASHI, C.; BOSCOLO, W.R.; SOARES, C.M. et al. Exigência de proteína digestível para larvas de tilápia do Nilo (Oreochromis niloticus) no período de reversão sexual. Revista Brasileira de Zootecnia, v.31, n.2, p.823-828, 2002.

LOWELL, T. Nutiriton and feeding of fish. New York:Van Nostrand Reinhold, 1989. p.11-18.

MCGOOGAN, B.B.; REIGH, R.C. Apparent digestibility of selected ingredients in red drum (Sciaenops ocellatus) diets. Aquaculture, v.14, p.233-244, 1996.

MEURER, F.; HAYASHI, C.; BOSCOLO, W.R. Digestibilidade aparente de alguns alimentos protéicos pela tilápia do Nilo (Oreochromis niloticus). Revista Brasileira de Zootecnia, v.32, n.6, p.1801-1809, 2003

MUKHOPADHYAY, N.; RAY, A.K. The apparet total and nutrient digestibility of sal seed (Shorea robusta) meal in rohu (Labeo rohita), fingerlings. Aquaculture Research, v.28, p.683-689, 1997.

NAKATANI, K.; AGOSTINHO, A.A.; BAUMGARTNER, G. et al. Ovos e larvas de peixes de agua doce. Maringá: EDUEM, 2001. 378p

PEZZATO, L.D.; CASTAGNOLLI, N.; ROSSI, F. Nutrição e alimentação de peixes. Viçosa, MG: Editora UFV, 2001. 72p.

PEZZATO, L.E.; MIRANDA, E.C.; BARROS, M.M. et al. Digestibilidade aparente de ingredientes pela tilápia do Nilo (Oreochromis niloticus). Revista Brasileira de Zootecnia, v.31, n.4, p.1595-1604, 2002.

ROBINSON, E.H.; WILSON, R.P. Nutrition and feeding. In: TUCKER, C.S. (Ed.) Channel catfish culture. New York: Elsevier, 1985. p.323-404.

SÁ, M.V.C.; FRACALOSSI, D.M. Exigência protéica e relação energia/ proteína para alevinos de piracanjuba (Bryconorbignyanus) Revista Brasileira de Zootecnia, v.31, n.1, p.1-10, 2002.

SIGNOR, A.; SIGNOR, A.A.; FEIDEN, A. et al. Exigência de proteína bruta de alevinos de Jundiá (Rhamdia quelen). Varia Cientia, v.4, n.1, p.79-89, 2004.

SIPAÚBA-TAVARES, L.H.S. Limnologia aplicada à aqüicultura Jaboticabal: Funep, 1995. 72p.

TEIXEIRA, B.; MACHADO, C.C.; FRACALOSSI, D.M. Exigência protéica em dietas para alevinos do dourado (Salminus brasiliensis). Acta Scientiarum. Animal Sciences, v.32, n.1, p.33-38, 2010.

URBINATI, E.C.; GONÇALVES, F.D. Pacu (Piaractus mesopotamicus). In: BALDISSEROTO, B.; GOMES, L.C. (Orgs.) Espécies nativas para a piscicultura no Brasil. Santa Maria: UFSM, 2005. p.225-255.

VIDAL JR., M.V.; DONZELE, J.L.; CAMARGO, A.C.S. et al. Níveis de proteína bruta para tambaqui (Colossoma macropomun), na fase de 30 a 250 gramas. Desempenho dos tambaquis. Revista Brasileira de Zootecnia, v.27, n.3, p.421-426, 1998. 